\title{
Performance of an acoustic telemetry system in a large fishway
}

\author{
Ki Won Jung ${ }^{1}$, Z. Daniel Deng ${ }^{1 *}$, Jayson J. Martinez ${ }^{1}$, David R. Geist ${ }^{1}$, Geoffrey A. McMichael',
} John R. Stephenson ${ }^{1}$ and Peter J. Graf ${ }^{2}$

\begin{abstract}
Background: The ability to track fish in the vicinity of dams and detect the presence of fish in fishways (also referred to as fish ladders) is critical to understanding the migration biology of upstream migrating fish and their passage success. Acoustic telemetry provides a valuable method within the telemetry toolbox, but has rarely been used in noisy, constrained, swift-flowing, and air-entrained environments such as fishways because of the perceived limitations of acoustic telemetry in such environments relative to other techniques such as radio telemetry. However, there have been no published studies that represent systematic evaluations of both detection efficiency based on number of transmitted signals and detection probabilities based on number of fish detected in fishways for acoustic telemetry. As such, the efficacy of acoustic telemetry in a fishway was evaluated using both controlled field experiments and movements of live fish at the Wanapum Dam fishway on the Columbia River in Washington State. In this study, the Juvenile Salmon Acoustic Telemetry System (JSATS) was selected because of its high carrier frequency (416.7 kHz) and short signal duration yielding good system resilience in shallow, noisy, and constrained environments.

Results: Detection efficiencies from the controlled field experiments were over $80 \%$ (mean \pm standard error $(\mathrm{SE})=85 \pm 2 \%)$ for most locations within the fishway at Wanapum Dam. Detection efficiency was nearly $100 \%$ (mean $\pm \mathrm{SE}=97 \pm 1 \%$ ) in the fishway entrance when the transmitters (also referred to as tags) were within $10 \mathrm{~m}$ of the hydrophones. The detection probabilities for the live fish experiment were $100 \%$ at all deployment locations.

Conclusions: This study suggests that a $416.7-\mathrm{kHz}$ acoustic telemetry system with binary phase shift-keyed encoding is capable of reliably detecting fish within a large fishway, thus providing a reliable tool to enable researchers to understand and study fish behavior and their fate near and in fishways.
\end{abstract}

Keywords: Acoustic telemetry, Fishways, Detection efficiency, Detection Probabilities, Migration

\section{Background}

Acoustic telemetry was first applied to the study of fish behavior decades ago [1], but recently, acoustic telemetry has become exceedingly popular and is playing an important role in fundamental and applied fish behavior research in both marine and freshwater systems [2-10]. In riverine systems with barriers, fishways (i.e., fish ladders) are often installed in an attempt to facilitate passage past the barrier and maintain longitudinal connectivity. Nonetheless, fish passage science is imperfect with not all fish successfully locating or ascending the fishway and those that do may experience sublethal alterations that influence

\footnotetext{
* Correspondence: zhiqun.deng@pnnl.gov

${ }^{1}$ Pacific Northwest National Laboratory, P.O. Box 999, Richland, WA 99352, USA

Full list of author information is available at the end of the article
}

fitness. For example, efficient upstream passage of adult salmonids through fishways at large hydroelectric dams may have implications for energy reserves available for spawning [11-13]. To know all of these, it may be important to be able to track the detailed movements of the fish from the moment they enter a dam till they leave it (regardless of successfully ascending the fishway or not). However, few studies [14] have been published on the application of acoustic telemetry in tracking fish within fishways or other confined spaces. Also, there have been no published studies that systematically evaluate both detection efficiency, based on the number of transmitted signals, and detection probabilities, based on the number of tagged fish detected, in fishways.

Many studies that involve detecting fish in confined spaces use passive integrated transponder (PIT tag) 
technology to detect fish at fixed points within juvenile bypass systems [15-18] or in fishways [19-23]. Studies have been conducted using a PIT tag with another telemetric technology, such as radio telemetry [13], by dual-tagging fish $[15,16,19]$ or only using a PIT tag $[17,18,20-24]$. Although it has an advantage in terms of longevity of the tag relative to other technologies, PIT tags have short detection ranges that typically are less than $1 \mathrm{~m}$ in the tags' long axis, perpendicular to the antenna [24]. Hence, PIT tags have lower detectability compared to other telemetry technologies, such as acoustic and radio telemetry, when a wide coverage area is required. As a result of the low detectability, the sample size of fish tagged may need to be considerably larger when conducting survival studies of migrating fish to achieve the same precision in the survival estimation [16]. Also, it is challenging to install PIT antennas on many passage routes such as through turbines or spillbays. Further, while PIT tags may provide detection data within the confined spaces of fishways, they cannot be detected in dam tailraces or forebays, making them ineffective for studies of overall passage behavior of migratory fish encountering large hydroelectric dams.

Radio telemetry also has been used in fishways by many researchers. For example, Gowans et al. [25] investigated the migratory behavior of adult Atlantic salmon through fish ladders, and Johnson et al. [26] studied the effect of the water velocity at fishway openings on the migratory behavior of adult Pacific lampreys. While radio telemetry is an effective tool for studying fish in shallow freshwater environments, an antenna exterior to the tagged fish is often used to transmit the radio signal [1]. However, an external antenna could become entangled [27, 28] and possibly reduce the swimming performance of fish if the antenna is long [29].

Acoustic telemetry has several advantages over radio telemetry and PIT technology. For example, it typically has long detection ranges, good performance in deep water, and capability of determining three-dimensional positions with high accuracy. Roscoe et al. [14] used an acoustic telemetry system in a fishway as a part of an evaluation of the upstream migration mortality of adult sockeye salmon. However, their study did not focus on evaluating the efficacy of acoustic telemetry in fishways and only reported detection probabilities of individual loggers based on number of fish detected compared to those known to have passed logger locations.

This paper presents the first published study that evaluates the efficacy of acoustic telemetry in a fishway. The study was conducted at Wanapum Dam using the Juvenile Salmon Acoustic Telemetry System (JSATS), which was originally developed by the U.S. Army Corps of Engineers to evaluate the survival and behavior of migrating juvenile salmonids [30-32]. Since its introduction, it has been used extensively in the Columbia River Basin [16, 30]. In this study, the JSATS was selected in part because it has a relatively short signal duration $(744 \mu \mathrm{s})$ compared to other acoustic telemetry systems. This decreases the likelihood of signal collision due to multipath signals from highly reflective structures such as fishway walls and the water surface. It was also selected because it has a high operating (carrier) frequency. Use of a higher carrier frequency is critical because background noise in environments close to dams is greater at lower frequency ranges [33]. Controlled field tests using JSATS tags as well as a field experiment using fish implanted with JSATS tags were conducted to measure both detection efficiency and detection probabilities. The objective of this study was to evaluate the detection capability of the JSATS technology in a confined space such as a fishway at a large dam. If this study is successful, the JSATS or other acoustic telemetry systems, with similar frequency and pulse duration, can allow researchers to better understand the behavior and survival of migrating fish in a confined space.

\section{Methods \\ Location}

Owned and operated by the Public Utility District Number 2 of Grant County, Wanapum Dam is located in southeast Washington State on the Columbia River, 669 river kilometers ( $\mathrm{rkm}$ ) from the mouth of the Columbia River (Fig. 1). The dam is 2,633 m long and $56 \mathrm{~m}$ tall and consists of a 10-unit powerhouse, a 12-bay spillway, and two fish ladders. The powerhouse has a generating capacity of 1,092 MW. All 10 units are six-blade Kaplan turbines.

\section{Acoustic tags}

For this study, two types of JSATS acoustic tags were used. The tags (Advanced Telemetry Systems, tag model SS130; Isanti, MN, USA) used for the controlled field testing were $12.00 \mathrm{~mm}$ long, $5.21 \mathrm{~mm}$ wide, and 3.77 $\mathrm{mm}$ thick; the tags weighed $0.438 \mathrm{~g}$ in air. These tags had an average source level of $155 \mathrm{~dB}$ re $1 \mu \mathrm{Pa}$ at $1 \mathrm{~m}$, a nominal pulse repetition period of $3.0 \mathrm{~s}$, and a nominal tag life of 33 days. The tags (Advanced Telemetry Systems, tag model SS300) used for the live fish experiment were $10.79 \mathrm{~mm}$ long, $5.26 \mathrm{~mm}$ wide, and $3.65 \mathrm{~mm}$ thick; they weighed $0.346 \mathrm{~g}$ in air. These tags had an average source level of $155 \mathrm{~dB}$ re $1 \mu \mathrm{Pa}$ at $1 \mathrm{~m}$, a nominal pulse repetition period of $4.2 \mathrm{~s}$, and a nominal tag life of 45 days. The pulse repetition period for each tag did not vary, although there was variability in the pulse repetition period across the tags.

\section{JSATS cabled receiver system}

A single JSATS cabled receiver system typically consists of one to four cabled hydrophones, a signal conditioning amplifier, a data acquisition computer that contains two 16-bit digital signal processing cards with field-programmable gate 


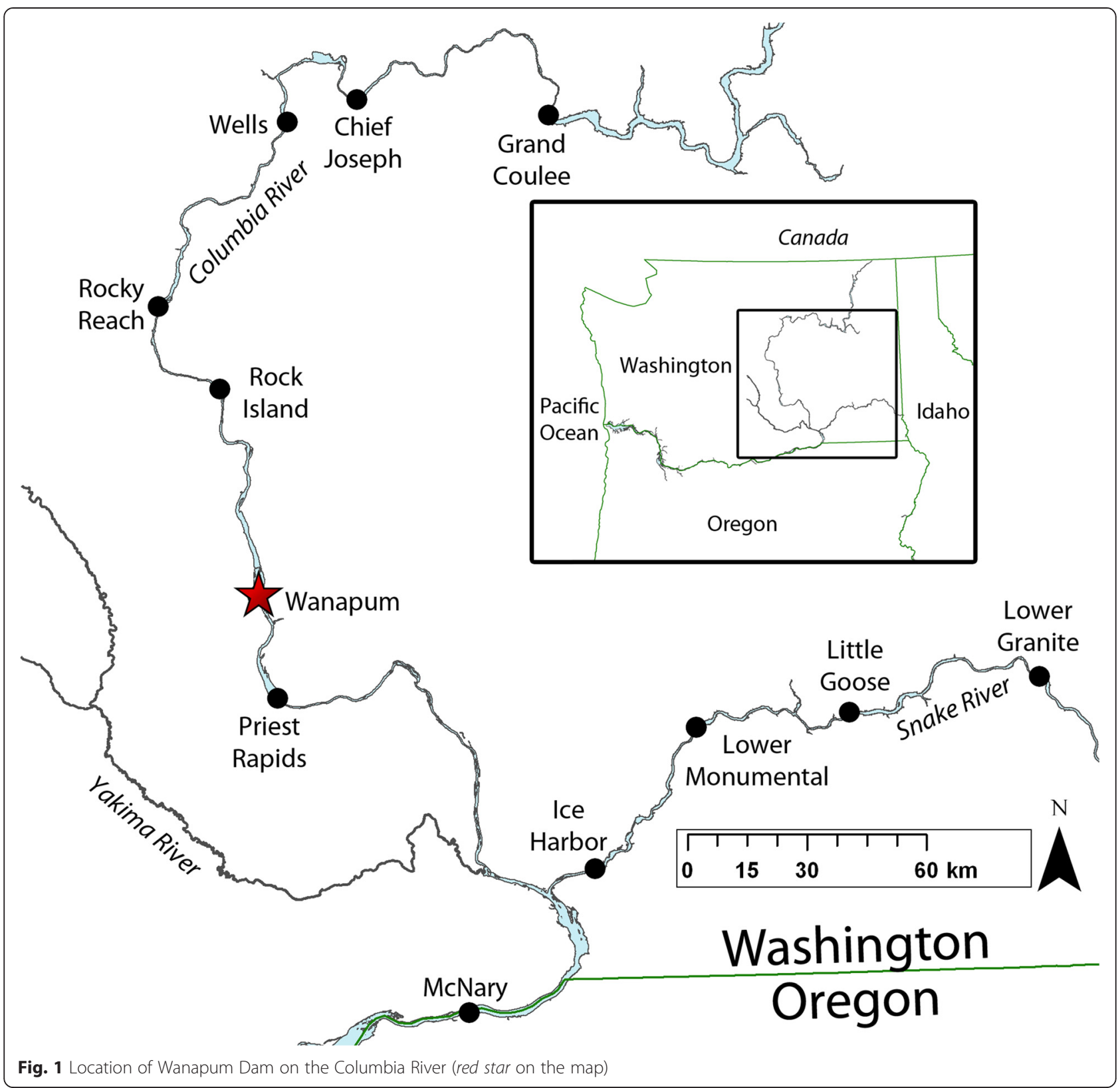

arrays each of which has two analog inputs, the detection software, the decoding software, a global positioning system (GPS) card, and a GPS antenna [30-32]. When an acoustic signal is transmitted from a tag, the hydrophones receive the signal, which is transferred to the amplifier where the signal is band-pass filtered around the carrier frequency of $416.7 \mathrm{kHz}$ and amplified. The filtered and amplified signal then is fed to the digital signal processing card, which contains detection software that checks the incoming data to determine if it contains a potential signal from a tag. If any of the hydrophone signals contain a potential detection from a tag, data are sampled at a frequency of $2.5 \mathrm{MHz}$, digitized with 16-bit resolution, and written to the hard drive using a filename that includes the high-accuracy GPS time. After the data are written to the hard drive, the decoding software [34] reads in the raw data and determines the presence of a tag code. If a tag code is detected, the decoding software checks the validity of the tag code by performing a cyclic redundancy check.

For this study, three JSATS cabled receiver systems were deployed in the north fish ladder system of Wanapum Dam (Fig. 2) at three different locations: (1) near the fish slide at the upper exit (i.e., water outfall structure into the forebay), (2) in the middle portion of the fish ladder, and (3) in the collection channels near the lower entrance. The system near the fish slide had two hydrophones ( $\mathrm{H} 1$ and $\mathrm{H} 2$ ) 


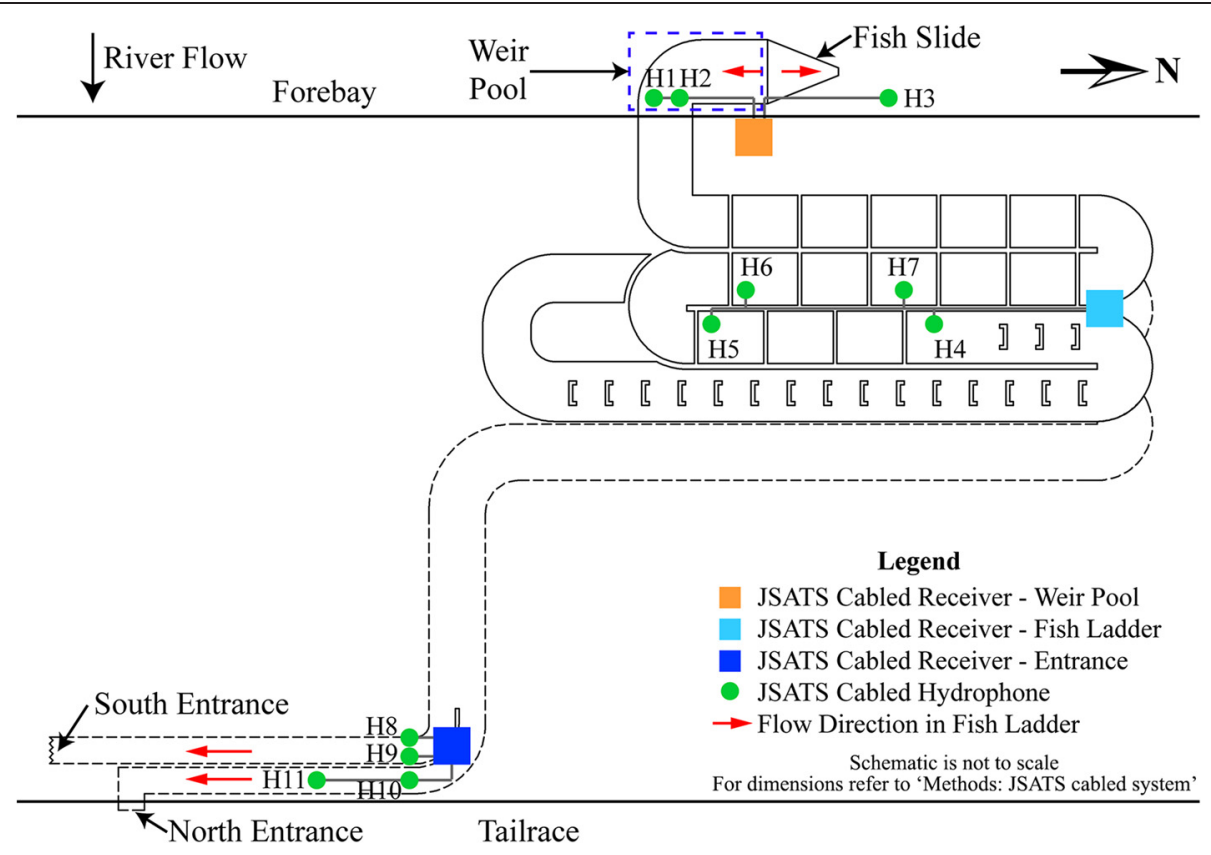

Fig. 2 Locations of the three deployed JSATS cabled receiver systems. The locations are in the left (east) bank fish ladder system at Wanapum Dam. Each receiving system monitored three to four hydrophones simultaneously

installed in the weir pool on 24 April 2014 (Fig. 3), just upstream of the fish slide. Also, one hydrophone (H3) was installed in the forebay near the outfall of the fish slide on 29 April 2014. The approximate water depth for both the weir pool and the forebay was 2 to $3 \mathrm{~m}$. The system located in the middle portion of the fish ladder had four hydrophones (H4 to H7), each of which was installed in different pool of the fish ladder on 7 May 2014. The dimension of each pool was $3 \times 5 \mathrm{~m}$, and the water depth was approximately $2 \mathrm{~m}$. The system deployed in the collection channels had pairs of hydrophones installed for both the south (H8 and H9) and north (H10 and H11) entrances on 29 April 2014. The width of both collection channels was approximately $5 \mathrm{~m}$, and the water depth was approximately 3 to $4 \mathrm{~m}$. Data were collected by all systems through 15 July 2014.

\section{Controlled field experiments}

After each JSATS cabled receiver system was installed, controlled field tests were carried out to evaluate the performance of the system. For the JSATS cabled receiver system near the weir pool of the fish slide (Fig. 3), the controlled experiments were conducted separately in the weir pool and the forebay below the weir pool. For these tests, three tags were attached to the line of a fishing rod and were immersed in the water at approximately the middle of the water column. A weight was
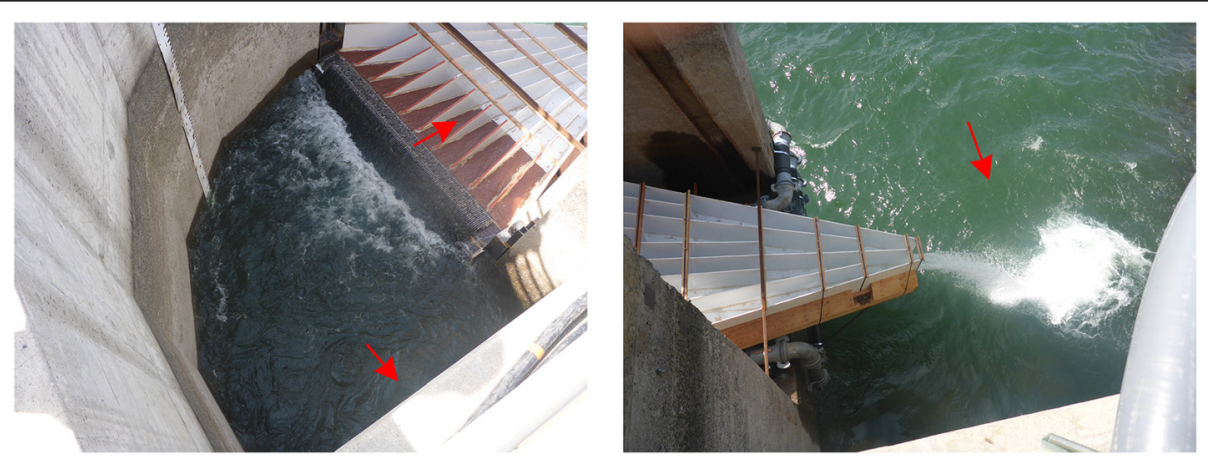

Fig. 3 The weir pool (left panel) and the forebay (right panel) at Wanapum Dam. The weir pool is located adjacent to the fish slide while the forebay is near the outfall of the fish slide. Fish swam out of the weir pool into the top of the fish slide and then passed into the forebay on their upstream migration. The direction of flow is shown with the red arrow. Water was pumped up from the forebay to provide flow down the fishway and into the upper end of the fish slide 
attached to the terminal end of the line in order for the tags to be fully immersed in the water. The separation between two adjacent tags was approximately $20 \mathrm{~cm}$ in the vertical direction, and the tags were approximately 2 to $3 \mathrm{~m}$ away from the hydrophones. Each test was performed for $10 \mathrm{~min}$. For the JSATS cabled receiver system inside the middle portion of fish ladder, the three tags were immersed into the water of each pool containing a hydrophone at approximately the middle of the water column, using the same setup as in the weir pool. Their distance from each hydrophone was approximately 2 to $3 \mathrm{~m}$. Each test was performed for $10 \mathrm{~min}$.

System performance data were also collected in the collection channels near the lower entrance of the fishway. Because of the limited access to the water in the collection channels, it was impossible to easily adjust the distance between the tags and the hydrophones by casting the fishing line. Thus, for the JSATS cabled receiver system in the collection channel, the three tags were attached to an approximately 2-m-long piece of rope (with a weight attached to the terminal end of the rope) and were positioned in the mid-depth of water under a 23-cm buoy. Another spool of rope was connected to this 23-cm buoy to control the distances between the tags and the hydrophones by letting the buoy float towards the desired positions. When the buoy was in position, a test was performed for $5 \mathrm{~min}$ at each location. At the south entrance, tests were conducted at distances of $1,10,30$, and $50 \mathrm{~m}$ from hydrophones $\mathrm{H} 8$ and H9. In the north entrance, tests were conducted at distances of 1,10 , and $20 \mathrm{~m}$ from hydrophone H10, which was farther upstream $(10,1$, and $9 \mathrm{~m}$, respectively, from the hydrophone $\mathrm{H} 11$ ).

For all tests, the results were processed by calculating the detection efficiency of each tag. The detection efficiency is defined as the ratio of the number of valid detections of the tag to the expected number of tag transmissions within the duration of the test (i.e., 5 or $10 \mathrm{~min}$ ).

\section{Background noise levels}

Background noise levels at each location in the confined spaces were estimated from data collected with the deployed JSATS cabled receiver systems. Before being deployed, each hydrophone was calibrated as a function of the frequency in a tank lined with anechoic materials in the Pacific Northwest National Laboratory's Bio-Acoustics and Flow Laboratory (BFL) [35]. The BFL is accredited by the American Association for Laboratory Accreditation (A2LA) to ISO/IEC 17025:2005, which is the international standard for calibration and testing laboratories. The hydrophones (Model SC001, Sonic Concepts Inc., Bothell, WA, USA) have a sensitivity of $-180 \mathrm{~dB}$ re $1 \mathrm{~V} / \mu \mathrm{Pa}$ at $416.7 \mathrm{kHz}$. From data files collected by the JSATS cabled receiver systems, portions that did not contain any transmissions of tag signals were selected and were considered to contain only background noise. Next, from the background noise portions, a frequency range between 375.0 and $458.0 \mathrm{kHz}$ was selected so the bandwidth of the signal becomes $20 \%$ of the carrier frequency of $416.7 \mathrm{kHz}$. Using the calibration data, the filtered voltage data were used to calculate the pressure spectral density, which was then integrated over the frequency range described above to compute the background noise level. For comparison, the background noise level in the BFL acoustic test tank also was estimated using the same types of instruments as in the field.

\section{Tagged fish experiment}

As part of a larger effort to evaluate upstream passage through a fish ladder with temporarily reduced flows and a modified exit structure at Wanapum Dam, 50 adult spring Chinook salmon were collected at the Priest Rapids Dam Off-Ladder Adult Fish Trap (rkm 639) from 26 to 29 April 2014, and were surgically implanted with acoustic transmitters (Advanced Telemetry Systems, tag model SS300) while anesthetized [36]. After each tag was implanted, the surgical opening was sutured [37], and the fish were released into the fish ladder at Priest Rapids Dam so they could freely migrate to Wanapum Dam (30 km upstream) on their way to their natal streams upstream of Rock Island Dam (rkm 730). These fish were monitored by the three JSATS cabled receiver systems installed at Wanapum Dam during the migration from Priest Rapids Dam to Rock Island Dam. The results were processed by calculating the detection probability and the median number of detections per tag for each of the three locations where JSATS cabled receiver systems were installed. The detection probability was defined to be the ratio of the detected number of fish to the expected number of fish. The expected number of fish is defined as the number of fish that were supposed to pass this route after the JSATS cabled receiver systems were installed. For example, 43 fish were expected in the weir pool because seven fish were confirmed to have already passed the dam via another route (the fishway on the other bank of the river). In addition, 49 fish were expected in the collection channels due to the fact that one fish passed before the JSATS cabled receiver system was deployed there. Finally, six fish were expected to pass the fish ladder because only six fish were confirmed to remain in the fish ladder when the JSATS cabled receiver system was deployed in this location.

\section{Results and discussion Background noise}

In the BFL acoustic test tank, the estimated background noise level (between 375.0 and $458.0 \mathrm{kHz}$ ) was $90 \mathrm{~dB}$ re $1 \mu \mathrm{Pa}$. The mean background noise level near the fish slide was $96 \mathrm{~dB}$ re $1 \mu \mathrm{Pa}$. In the fish ladder, the mean 
background noise level was $93 \mathrm{~dB}$ re $1 \mu \mathrm{Pa}$, and in the collection channels, the mean background noise levels were $101 \mathrm{~dB}$ re $1 \mu \mathrm{Pa}$ and $95 \mathrm{~dB}$ re $1 \mu \mathrm{Pa}$ for the south entrance and the north entrance, respectively.

\section{Controlled field tests}

For the JSATS cabled receiver system deployed near the fish slide, the detection efficiency for each hydrophone is presented in Table 1 . The detection efficiencies for hydrophones $\mathrm{H} 1$ and $\mathrm{H} 2$ individually ranged from 51 to $69 \%$, and the detection efficiencies for the immediate forebay (hydrophone H3) ranged from 82 to $90 \%$. Because both hydrophones $\mathrm{H} 1$ and $\mathrm{H} 2$ were located in the same weir pool, the combined detection efficiency of these two hydrophones is presented to represent the detection efficiency of the transmitted signal in the weir pool. As a result, the combined detection efficiencies for the weir pool were higher than $80 \%$ for all three test tags.

For the system deployed in the middle portion of the fish ladder, downstream of the weir pool, each hydrophone represents the pool in the fish ladder in which it was installed. Among 12 scenarios (i.e., three tags at four pool locations), detection efficiencies in seven scenarios were greater than $80 \%$ (Table 2). Compared to the other locations, the system in the middle portion of the fish ladder had lower detection efficiency when tags were held within $3 \mathrm{~m}$ of each hydrophone (H4 to H7). This was the case even though the background noise in the fish ladder at that location was lower than those at the other locations. This lower detection efficiency was likely due to the relatively high water velocity and shallow water inside the fish ladder.

For the system deployed in the collection channels, a pair of two hydrophones was installed in both the south (H8 and H9) and north (H10 and H11) entrances. In the south entrance, the mean detection efficiency was $86 \%$ for $\mathrm{H} 8$ and $96 \%$ for $\mathrm{H} 9$ when the tags were $1 \mathrm{~m}$ away from the hydrophones but decreased to $74 \%$ and $78 \%$ when the distance increased to $10 \mathrm{~m}$ (Fig. 4). When the tags were 30 to $50 \mathrm{~m}$ away from the hydrophones, the mean detection efficiency of an individual hydrophone ranged from $18-53 \%$. The mean combined detection

Table 1 Detection efficiency near the weir pool at Wanapum Dam

\begin{tabular}{lllll}
\hline & \multicolumn{3}{l}{ Detection efficiency in the weir pool } & $\begin{array}{l}\text { Detection efficiency } \\
\text { in the forebay }\end{array}$ \\
\cline { 2 - 4 } Tag number & $\mathrm{H} 1(\%)$ & $\mathrm{H} 2(\%)$ & Combined (\%) & H3 (\%) \\
\hline 1 & 68 & 51 & 85 & 87 \\
2 & 59 & 56 & 81 & 90 \\
3 & 69 & 54 & 90 & 82 \\
Mean & 65 & 54 & 85 & 86 \\
\hline
\end{tabular}

Locations of the hydrophones and the JSATS cabled receiver system are indicated in Fig. 2
Table 2 Detection efficiency in the middle portion of the fish ladder at Wanapum Dam

\begin{tabular}{lllll}
\hline \multirow{2}{*}{ Tag number } & \multicolumn{4}{l}{ Detection efficiency } \\
\cline { 2 - 5 } & $\mathrm{H} 4(\%)$ & $\mathrm{H} 5(\%)$ & $\mathrm{H} 6(\%)$ & $\mathrm{H} 7(\%)$ \\
\hline 1 & 60 & 70 & 65 & 78 \\
2 & 81 & 86 & 73 & 80 \\
3 & 90 & 93 & 84 & 81 \\
Mean & 77 & 83 & 74 & 80 \\
\hline
\end{tabular}

Locations of the hydrophones and the JSATS cabled receiver system are indicated in Fig. 2

efficiency was greater than $90 \%(98 \%$ and $94 \%)$ up to the distance of $10 \mathrm{~m}$ but dropped below $80 \%$ (71 \% and $56 \%)$ when the tags were $30 \mathrm{~m}$ or more away from the hydrophones. When one-way ANOVA $(p<0.05)$ and Tukey's HSD $(p<0.05)$ were applied to the combined detection efficiency, a statistically significant difference in group means between the groups was found $(p=7.49 \times$ $\left.10^{-7}\right)$, but there was no significant difference found between the data at $1 \mathrm{~m}$ and at $10 \mathrm{~m}(p=0.42)$. On the other hand, the mean detection efficiency of individual hydrophones was greater than $80 \%$ (82 to $99 \%$ ), and the mean combined detection efficiency was at least $98 \%$ for all distances in the north entrance (Table 3). The mean detection efficiency of individual hydrophones was consistently higher at the north entrance than at the south entrance when comparing the results from the same distance $(1$ or $10 \mathrm{~m})$. This observation is consistent with measurements of higher background noise levels at the south entrance (i.e., by approximately $6 \mathrm{~dB}$ ) than at the north entrance. Overall, the mean combined detection efficiency ranged from 94 to $99 \%$ if the tags were within

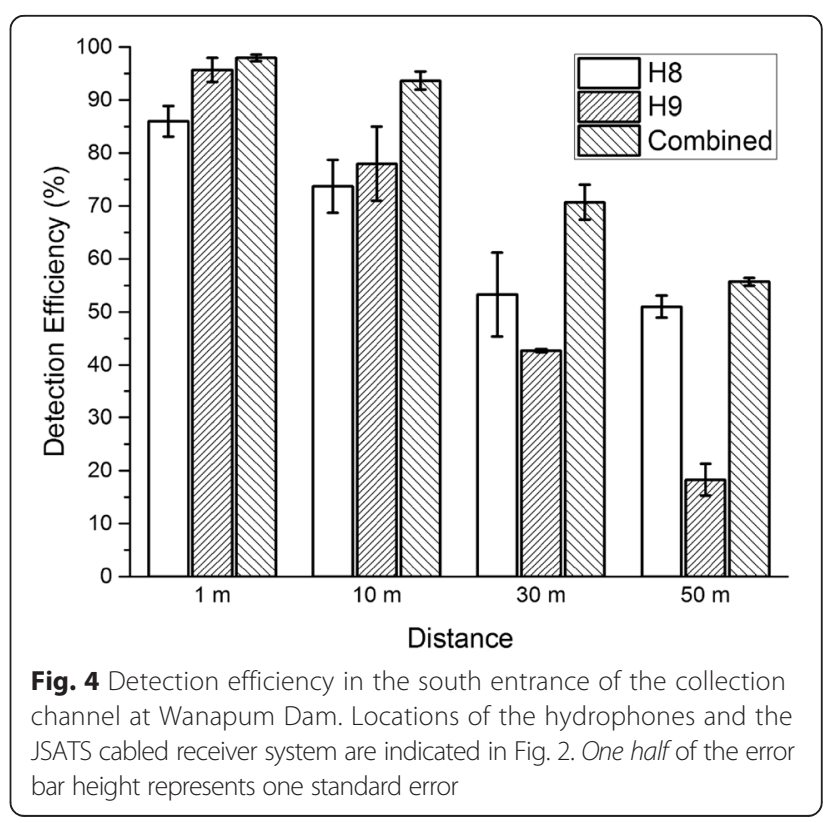


Table 3 Detection efficiency in the north entrance of the collection channel at Wanapum Dam

\begin{tabular}{|c|c|c|c|c|c|c|c|c|c|}
\hline \multirow[b]{2}{*}{ Tag number } & \multicolumn{3}{|c|}{ Detection efficiency (\%) } & \multicolumn{3}{|c|}{ Detection efficiency (\%) } & \multicolumn{3}{|c|}{ Detection efficiency (\%) } \\
\hline & $\mathrm{H} 10$ (1 m) & $\mathrm{H} 11$ (10 m) & Combined & $\mathrm{H} 10$ (10 m) & $\mathrm{H} 11$ (1 m) & Combined & $\mathrm{H} 10$ (20 m) & $\mathrm{H} 11$ (9 m) & Combined \\
\hline 1 & 86 & 88 & 97 & 88 & 100 & 100 & 88 & 87 & 97 \\
\hline 2 & 96 & 78 & 99 & 87 & 99 & 99 & 77 & 97 & 100 \\
\hline 3 & 98 & 93 & 99 & 91 & 99 & 99 & 82 & 97 & 99 \\
\hline Mean & 93 & 86 & 98 & 89 & 99 & 99 & 82 & 94 & 99 \\
\hline
\end{tabular}

Locations of the hydrophones and the JSATS cabled receiver system are indicated in Fig. 2

$10 \mathrm{~m}$ of individual hydrophones at each location in the collection channels.

\section{Live fish experiment}

For all three locations, the detection probability was $100 \%$ (Table 4). Here, the expected number of fish is calculated based on the number of fish that were expected to pass the individual route during the time each JSATS cabled receiver system was deployed at each location. For comparison, Roscoe et al. [14] reported detection probabilities of $91 \%, 75 \%$, and $100 \%$ at the bottom, the midpoint, and the top pool of the fishway at Seton Dam in British Columbia, respectively. The difference in detection probabilities between the two studies is likely due to the fact that both the carrier frequency and the pulse duration were different for the systems used in each study. The JSATS uses the carrier frequency of $416.7 \mathrm{kHz}$, while the system used by Roscoe et al. had a carrier frequency of $69 \mathrm{kHz}$. Systems that use lower carrier frequencies typically have longer detection ranges in lentic and marine environments than systems that use higher carrier frequencies. However, when working at and near hydroelectric dams, background noise usually affects systems with lower carrier frequencies more because the background noise is typically significantly greater at lower frequency ranges than at higher frequency ranges [33]. In addition, the JSATS utilizes a 744- $\mu$ s pulse duration compared to the 10-ms pulse duration of the system used by Roscoe et al. [14]. With the narrow width and shallow water depth confined by highly reflective walls in fishways, fewer collisions between the transmitted signals and reflected signals would be expected at the 744- $\mu$ s pulse duration.

Table 4 Overall detection probabilities and median number of detections per fish at Wanapum Dam

\begin{tabular}{lllll}
\hline Location & $\begin{array}{l}\text { Expected } \\
\text { number } \\
\text { of fish }\end{array}$ & $\begin{array}{l}\text { Detected } \\
\text { number } \\
\text { of fish }\end{array}$ & $\begin{array}{l}\text { Detection } \\
\text { probability (\%) }\end{array}$ & $\begin{array}{l}\text { Median number } \\
\text { of detections } \\
\text { per fish }\end{array}$ \\
\hline $\begin{array}{l}\text { Collection } \\
\text { channels }\end{array}$ & 49 & 49 & 100 & 4927 \\
Fish ladder & 6 & 6 & 100 & 41 \\
Weir pool & 43 & 43 & 100 & 86 \\
\hline
\end{tabular}

The number of tagged fish expected in the fish ladder was small because the JSATS cabled receiver system was installed at that location on 7 May 2014, when only six of the tagged fish had not yet been confirmed to have passed the dam. The expected number of fish in the weir pool was 43 because seven fish passed the dam via another route that was not covered by the JSATS cabled receiver systems. Fish spent a median of 3.3 days in the collection channels, although most fish would enter and leave the collection channel multiple times before moving all the way through the ladder. On the other hand, fish spent a median of 10.9 and 16.1 min within the detection range of the JSATS cabled receiver systems in the middle portion of the fish ladder and in the weir pool, respectively. Therefore, the hydrophones in the collection channels had significantly higher numbers of detections than hydrophones installed in the weir pool and the middle portion of the fish ladder.

\section{Conclusions}

Controlled field experiments demonstrated that the JSATS cabled receiver systems can reliably detect the acoustic signal from tags in confined spaces, including the fish ladder entrance (i.e., collection channels), inside the fish ladder, and in the weir pool. The detection efficiency of static tags, based on number of transmitted signals, exceeded $80 \%$ for most locations and ranged from 94 to $99 \%$ in the fish ladder entrance when the tags were within $10 \mathrm{~m}$ from all hydrophones. This result may suggest that the JSATS cabled receiver systems can detect the tagged fish in confined spaces such as fishways. A small field study consisting of 50 adult spring Chinook salmon implanted with acoustic tags confirmed the findings of the controlled field experiments. The JSATS cabled receiver systems had a $100 \%$ detection probability of the tagged fish at each deployment location. Even at the locations with the relatively low median number of detections of 41 (fish ladder) and 86 (weir pool), due to the short residence time of the fish, detection probabilities were $100 \%$, although for the former sample size, there were only six fish. The results of this research will allow scientists to better understand the behavior of fish in confined spaces such as fishways and to design better migration studies involving fishways. The need to implant an 
additional PIT tag in fish used for a study that concerns one-way migration also might be eliminated if the only purpose of the PIT tag is to confirm the presence of the tagged fish in a fishway. In addition, the results reported in this study are applicable to other acoustic telemetry technologies that have a carrier frequency and pulse duration comparable to JSATS.

\section{Abbreviations}

JSATS: Juvenile Salmon Acoustic Telemetry System; PIT: passive integrated transponder; GPS: global positioning system; A2LA: American Association for Laboratory Accreditation; BFL: Bio-Acoustics and Flow Laboratory.

\section{Competing interests}

The authors declare that they have no competing interests.

\section{Authors' contributions}

DRG, GAM, PJG, and ZDD conceived, designed, and coordinated this study. KWJ, JRS, and JJM carried out the data acquisition, and KWJ, JJM, and ZDD carried out the data analysis. All authors wrote and approved the manuscript.

\section{Acknowledgements}

The authors would like to thank the Grant County Public Utility District for providing the opportunity to conduct this study and for funding the work. Without the help of Tao Fu, Yong Yuan, Kyle Larson, Richard Brown, P. Scott Titzler, Kate Deters, Ricardo Walker, Bryan Jones, and Stephanie Liss, this study, including both the controlled experiments and the live fish experiments, would not have been possible. For the live fish experiments, all animal handling was performed under an approval (2014-09) issued by the Institutional Animal Care and Use Committee of Battelle.

\section{Author details}

${ }^{1}$ Pacific Northwest National Laboratory, P.O. Box 999, Richland, WA 99352, USA. ${ }^{2}$ Grant County Public Utility District, Ephrata, WA, USA.

\section{Received: 8 December 2014 Accepted: 14 April 2015}

Published online: 14 July 2015

\section{References}

1. Cooke S, Hinch S, Lucas M, Lutcavage M. Biotelemetry and biologging. Fisheries Techniques. 2013;819-860.

2. Michel C, Ammann A, Chapman E, Sandstrom P, Fish H, Thomas M, et al. The effects of environmental factors on the migratory movement patterns of Sacramento River yearling late-fall run Chinook salmon (Oncorhynchus tshawytscha). Environ Biol Fish. 2013;96:257-71.

3. Johnson SL, Power JH, Wilson DR, Ray J. A comparison of the survival and migratory behavior of hatchery-reared and naturally reared steelhead smolts in the Alsea River and Estuary, Oregon, using acoustic telemetry. N Am J Fish Manag. 2010;30:55-71.

4. Perry RW, Skalski JR, Brandes PL, Sandstrom PT, Klimley AP, Ammann A, et al. Estimating survival and migration route probabilities of juvenile Chinook Salmon in the Sacramento-San Joaquin River Delta. N Am J Fish Manag. 2010;30:142-56.

5. Trotter AA, Blewett DA, Taylor RG, Stevens PW. Migrations of common snook from a Tidal River with implications for skipped spawning. Trans Am Fish Soc. 2012;141:1016-25.

6. McCauley MM, Cerrato RM, Sclafani M, Frisk MG. Diel behavior in white perch revealed using acoustic telemetry. Trans Am Fish Soc. 2014;143:1330-40.

7. Childs A-R, Cowley P, Næsje T, Booth A, Potts W, Thorstad E, et al. Do environmental factors influence the movement of estuarine fish? A case study using acoustic telemetry. Estuar Coast Shelf Sci. 2008;78:227-36.

8. Vinebrooke R, Welch DW, Melnychuk MC, Rechisky ER, Porter AD, Jacobs $M C$, et al. Freshwater and marine migration and survival of endangered Cultus Lake sockeye salmon (Oncorhynchus nerka) smolts using POST, a large-scale acoustic telemetry array. Can J Fish Aquat Sci. 2009;66:736-50.

9. Heupel MR, Simpfendorfer CA, Fitzpatrick R. Large-scale movement and reef fidelity of grey reef sharks. PLoS ONE. 2010;5, e9650.
10. Abecasis D, Bentes L, Erzini K. Home range, residency and movements of Diplodus sargus and Diplodus vulgaris in a coastal lagoon: connectivity between nursery and adult habitats. Estuar Coast Shelf Sci. 2009;85:525-9.

11. Gowans ARD, Armstrong JD, Priede IG, McKelvey S. Movements of Atlantic salmon migrating upstream through a fish-pass complex in Scotland. Ecol Freshw Fish. 2003:12:177-89.

12. Geist DR, Abernethy CS, Blanton SL, Cullinan VI. The use of electromyogram telemetry to estimate energy expenditure of adult fall Chinook salmon. Trans Am Fish Soc. 2000;129:126-35.

13. Brown RS, Geist DR, Mesa MG. Use of electromyogram telemetry to assess swimming activity of adult spring Chinook salmon migrating past a Columbia River Dam. Trans Am Fish Soc. 2006;135:281-7.

14. Roscoe D, Hinch S, Cooke S, Patterson D. Fishway passage and post-passage mortality of up-river migrating sockeye salmon in the Seton River. British Columbia River Res Appl. 2011;27:693-705.

15. Burke BJ, Jepson MA. Performance of passive integrated transponder tags and radio tags in determining dam passage behavior of adult Chinook salmon and steelhead. N Am J Fish Manag. 2006;26:742-52.

16. Brown R, Oldenburg E, Seaburg A, Cook K, Skalski J, Eppard M, et al. Survival of seaward-migrating PIT and acoustic-tagged juvenile Chinook salmon in the Snake and Columbia Rivers: an evaluation of length-specific tagging effects. Anim Biotelem. 2013;1:8.

17. Muir WD, Smith SG, Williams JG, Sandford BP. Survival of juvenile salmonids passing through bypass systems, turbines, and spillways with and without flow deflectors at Snake River dams. N Am J Fish Manag. 2001;21:135-46.

18. Axel G, Prentice E, Sandford BP. PIT-tag detection system for large-diameter juvenile fish bypass pipes at Columbia River basin hydroelectric dams. N Am J Fish Manag. 2005;25:646-51.

19. Matter AL, Sandford BP. A comparison of migration rates of radio-and PIT-tagged adult Snake River Chinook salmon through the Columbia River hydropower system. N Am J Fish Manag. 2003;23:967-73.

20. McCutcheon CS, Prentice EF, Park DL. Passive monitoring of migrating adult steelhead with PIT tags. N Am J Fish Manag. 1994;14:220-3.

21. Thiem J, Binder T, Dawson J, Dumont P, Hatin D, Katopodis C, et al. Behaviour and passage success of upriver-migrating lake sturgeon Acipenser fulvescens in a vertical slot fishway on the Richelieu River, Quebec. Canada Endanger Species Res. 2011;15:1-11.

22. Foulds W, Lucas MC. Extreme inefficiency of two conventional, technical fishways used by European river lamprey (Lampetra fluviatilis). Ecol Eng. 2013;58:423-33.

23. Franklin AE, Haro A, Castro-Santos T, Noreika J. Evaluation of nature-like and technical fishways for the passage of alewives at two coastal streams in New England. Trans Am Fish Soc. 2012;141:624-37.

24. Castro-Santos T, Haro A, Walk S. A passive integrated transponder (PIT) tag system for monitoring fishways. Fish Res. 1996;28:253-61.

25. Gowans A, Armstrong J, Priede I. Movements of adult Atlantic salmon in relation to a hydroelectric dam and fish ladder. J Fish Biol. 1999;54:713-26.

26. Johnson EL, Caudill CC, Keefer ML, Clabough TS, Peery CA, Jepson MA, et al. Movement of radio-tagged adult Pacific lampreys during a large-scale fishway velocity experiment. Trans Am Fish Soc. 2012;141:571-9.

27. Cooke SJ, Bunt CM. Assessment of internal and external antenna configurations of radio transmitters implanted in smallmouth bass. N Am J Fish Manag. 2001;21:236-41.

28. Adams NS, Rondorf DW, Evans SD, Kelly JE, Perry RW. Effects of surgically and gastrically implanted radio transmitters on swimming performance and predator avoidance of juvenile Chinook salmon (Oncorhynchus tshawytscha). Can J Fish Aquat Sci. 1998;55:781-7.

29. Murchie K, Cooke S, Schreer J. Effects of radio-transmitter antenna length on swimming performance of juvenile rainbow trout. Ecol Freshw Fish. 2004;13:312-6.

30. McMichael GA, Eppard MB, Carlson TJ, Carter JA, Ebberts BD, Brown RS, et al. The juvenile salmon acoustic telemetry system: a new tool. Fisheries. 2010;35:9-22.

31. Deng ZD, Weiland MA, Fu T, Seim TA, LaMarche BL, Choi EY, et al. A cabled acoustic telemetry system for detecting and tracking juvenile salmon: Part 2. Three-dimensional tracking and passage outcomes. Sensors. 2011;11:5661-76.

32. Weiland MA, Deng ZD, Seim TA, LaMarche BL, Choi EY, Fu T, et al. A cabled acoustic telemetry system for detecting and tracking juvenile salmon: Part 1. Engineering design and instrumentation. Sensors. 2011;11:5645-60.

33. Ingraham JM, Deng ZD, Martinez JJ, Trumbo BA, Mueller RP, Weiland MA. Feasibility of tracking fish with acoustic transmitters in the Ice Harbor Dam tailrace. Sci Rep. 2014;4. 
34. Ingraham J, Deng Z, Li X, Fu T, McMichael G, Trumbo B. A fast and accurate decoder for underwater acoustic telemetry. Rev Sci Instrum. 2014;85:074903.

35. Deng Z, Weiland M, Carlson T, Eppard MB. Design and instrumentation of a measurement and calibration system for an acoustic telemetry system. Sensors. 2010;10:3090-9.

36. Summerfelt RC, Smith L, Schreck C, Moyle P. Anesthesia, surgery, and related techniques. Methods for fish biology American Fisheries Society, Bethesda, Maryland. 1990;8:2.

37. Deters KA, Brown RS, Boyd JW, Eppard MB, Seaburg AG. Optimal suturing technique and number of sutures for surgical implantation of acoustic transmitters in juvenile salmonids. Trans Am Fish Soc. 2012;141:1-10.

\section{Submit your next manuscript to BioMed Central} and take full advantage of:

- Convenient online submission

- Thorough peer review

- No space constraints or color figure charges

- Immediate publication on acceptance

- Inclusion in PubMed, CAS, Scopus and Google Scholar

- Research which is freely available for redistribution 